\title{
A 13-YEAR-OLD FEMALE WITH BARDET- BIEDL SYNDROME - A CASE REPORT
}

\author{
SYED NESAR AHMED ${ }^{1}$, MD ABU SHAHIN ${ }^{2}$, ROMAL CHOWDHURY ${ }^{3}$, ALAMGIR MUSTAK AHAMMAD ${ }^{4}$, MD \\ NAHIDUZZAMAN SHAZZAD ${ }^{5}$, MD RAFIQUL ALAM ${ }^{6}$, MA JALIL CHOWDHURY7
}

\begin{abstract}
:
Bardet Biedl syndrome is a rare disease. A case report is presented here where a 13 years old girl presented with obesity, night blindness, learning difficulties and polydactyly. Obesity and night blindness started from since childhood. Her milestones of development were normal but having some learning difficulties. Her parents are healthy as well as her siblings. On examination she looks apathy, extreme obese, having polydactyly and retinitis pigmentosa and high B.P. On laboratory findings there is only dyslipidaemia. On the basis of clinical features she was diagnosed as a case of Bardet-Biedl syndrome.
\end{abstract}

Key words: Bardet Biedl syndrome, Female child, Normal stature

Received: 08 September 2014

Accepted: 19 December 2014

\section{Introduction:}

Bardet Biedl syndrome is a rare autosomal recessive condition with a wide spectrum of clinical features. Bardet-Biedl syndrome (BBS) is characterized by rodcone dystrophy, truncal obesity, postaxial polydactyly, cognitive impairment, male hypogonadotrophic hypogonadism, complex female genitourinary malformations, and renal abnormalities ${ }^{\mathbf{1}}$. The syndrome is named after Georges Bardet and Arthur $\mathrm{Bied1}^{2}$. Bardet-Biedl syndrome (BBS) is a rare autosomal recessive disorder. BBS was first described by Bardet and Biedl in the $1920^{2}$. The principal manifestations are rod-cone dystrophy (Retinitis pigmentosa), postaxial polydactyly, central obesity, mental retardation, hypogonadism, and renal dysfunction. Other features like hepatic fibrosis, diabetes mellitus, neurological, speech and language deficits, behavioral traits, facial dysmorphism, dental anomalies and developmental delay are not always present.

The diagnosis of Bardet-Biedl syndrome (BBS) is established by clinical findings. Beales et al [1999] and Beales et al have suggested that the presence of four primary features or three primary features plus two secondary features is diagnostic ${ }^{\mathbf{3}}$ (Table-1).

Table-I

Modified diagnostic criteria ${ }^{3}$ (Four features are required to be present of or Three primary plus two secondary features are required)

\begin{tabular}{ll}
\hline Primary Features & Secondary Features \\
\hline 1. Rod-cone Dystrophy & 1. Speech disorder/Delay \\
2. Obesity & 2. Strabismus/cataracts/astigmatism \\
3. Polydactyly & 3. Brachydactyly/ syndactyly \\
4. Learning Disabilities & 4. Developmental delay \\
5. Hypogonadism in males & 5. Nephrogenic diabetes insipidus \\
6. Renal Anomalies & 6. Ataxia/poor coordination/imbalance \\
& 7. Mild spasticity \\
& 8. Dental crowding/hypodontia/small roots \\
& 9. Left ventricular hypertrophy/congenital heart disease \\
\hline
\end{tabular}

1. Phase-A student, Department of Pulmonology, NIDCH

2. Assistant professor, Department of Rheumatology, BSMMU

3. Phase-A student, Department of Pulmonology, NIDCH

4. Phase-B student, Department of Rheumatology, BSMMU

5. Medical officer, Department of Rheumatology, BSMMU

6. Associate Professor, Department of Internal Medicine, BSMMU

7. Professor, Department of Internal Medicine, BSMMU

Correspondence: Dr. Syed Nesar Ahmed, MD, Pulmonology, Resident, Phase-A, NIDCH (National Institute of Chest Disease and Hospital), Telephone: +880-1913481375, E-mail: litonahmed2003@yahoo.com 


\section{Case report:}

A 13-year-old female (Figure-1) was admitted in medicine unit of Bangabandhu Sheikh Mujib Medical University (BSMMU) with the complaints of progressive weight gain and night blindness since childhood. Her parents enrolled her in a school, but she eventually dropped out because of poor learning capability. Her milestones of development was normal. She is the fourth children from a non-consanguineous marriage. Her parents are healthy as well as her siblings. None of her maternal and paternal uncles has such type of problems.

On examination she had apathy, depressed look, puffy face, found to be obese with weight $97 \mathrm{~kg}$, height $152 \mathrm{~cm}$

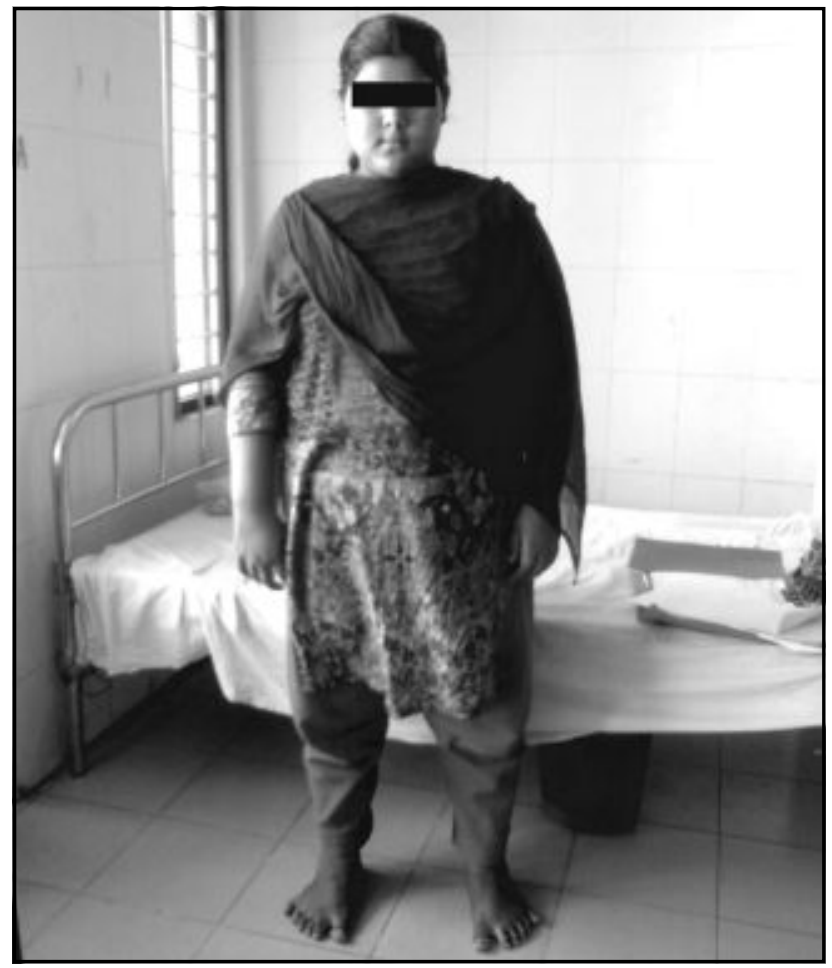

Fig.-1

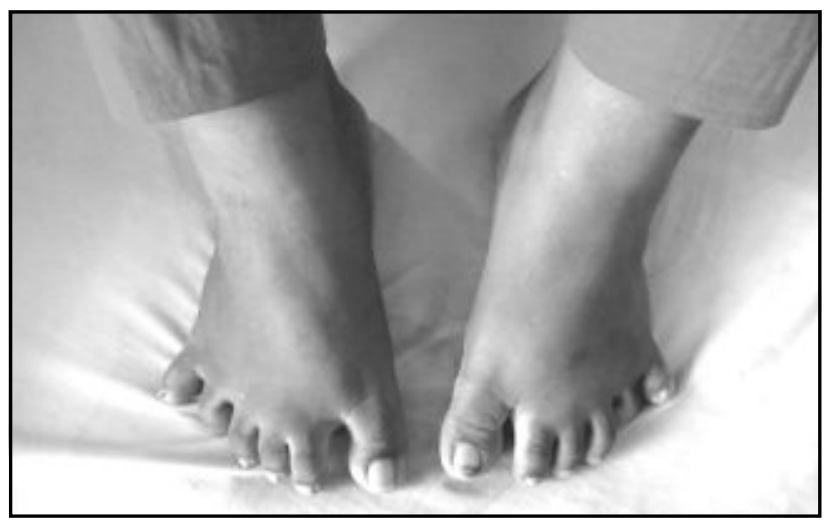

Fig.-2

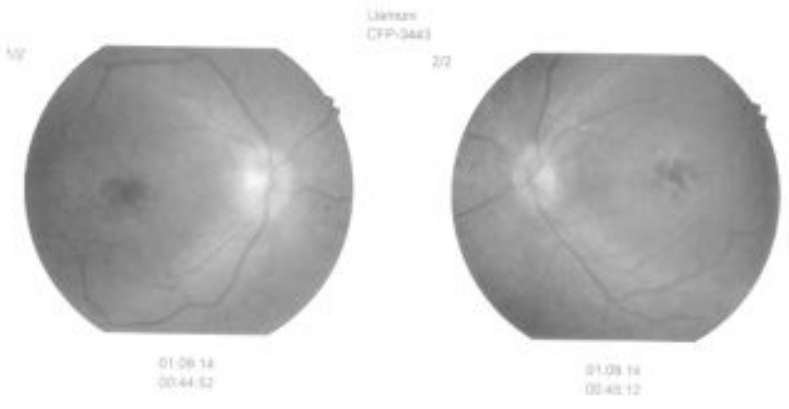

Fig.-3

and a BMI of 41, B.P: $140 / 85 \mathrm{mmHg}$, polydactyly on both feet ( Figure-2), MMSE score 22 out of 30, IQ 65 , retinitis pigmentosa on fundoscopy (Figure-3). Other systemic examinations including genital examinations reveals normal.

Laboratory examination including complete blood count, OGTT, SGPT, S.Creatinine, S.TSH, FT4, S.prolactin, urinalysis, ultrasonography of whole abdomen were found to be normal except F.lipid profile- S.Cholesterol $224 \mathrm{mg} / \mathrm{dl}$, S.TG- $236 \mathrm{mg} / \mathrm{dl}$, HDL $36 \mathrm{mg} / \mathrm{dl}$ and LDL $139 \mathrm{mg} / \mathrm{dl}$.

We ultimately diagnosed the patient as Bardet-Biedl syndrome (BBS) on clinical background.

\section{Discussion:}

The syndrome was described by Bardet Biedl in the 1920. It was later erroneously coupled with another disorder described by Laurence and Moon and was consequently referred to as Laurence - Moon-Biedl syndrome. BBS is distinguished from the much rarer Laurence- Moon syndrome, in which retinal pigmentary degeneration, mental retardation and hypogonadism occur in conjunction with progressive spastic paraparesis and distal muscle weakness but without polydactyly $\mathbf{4 , 5}$. The prevalence of BBS is 1:160000 in Europe and North America ${ }^{6}$ although higher incidence has been reported in the isolated populations of Newfoundland $[1: 13000]^{\mathbf{7}}$ and Kuwait $[1: 17000]^{7}$.

Retinal dystrophy $(100 \%)$ is the first major feature of the disorder. It is found occasionally in the first decade but present in almost all patients by the second decade $^{8}$. The reported case noticed night blindness at the age of 5 years.

Obesity is the second major feature of BBS, with a frequency of 72-96 percent depending on measurement criteria. Obesity usually begins in childhood and the severity increases with age, with the majority of cases exhibiting symptoms within the first year of life $^{3}$. Our reported case developed obesity at the age of 4 years. 
Limb-abnormalities are the third major feature of BBS. Limb deformities have been reported at varying frequencies ${ }^{\mathbf{3}, 9}$. Of these, post-axial polydactyly, polydactyly, and brachydactyly of both hands and feet are most common. Partial syndactyly, fifth finger clinodactyly and a prominent gap between the first and second toes are sometimes associated ${ }^{3}$. It is presented only in both feet of our reported case.

Mental retardation is a more disputed feature of BBS. Recently, objective IQ tests determined that only a minority of patients are mentally retarded. An IQ of 79 or below is found in 44 per cent of BBS patients. The decrease in IQ level correlates with the presence of visual handicap ${ }^{3,9}$. Our reported case also have this feature.

Hypo-genitalism is reportedly more frequently in BBS males than females ${ }^{3}$. In BBS females, genital abnormalities encompass a wide range, including hypoplastic fallopian tubes, uterus, and ovaries, partial and complete vaginal atresia, absent vaginal orifice, and absent urethral orifice ${ }^{\mathbf{1 0}, \mathbf{1 1}}$. Bardet-Biedl syndrome males have small penis and testes $(88 \%)^{9}$. Renal failure is the major cause of morbidity and early mortality in BBS. A wide range of renal abnormalities has been described (chronic renal failure, parenchymal cysts, calyceal clubbing, fetal lobulation, scarring, unilateral agenesis, dysplastic kidneys, renal calculi, vesico-ureterix reflux. These features are absent in our reported case.

In 1999, modified diagnostic criteria were defined after a study conducted in England in 109 BBS patients ${ }^{3}$. Patients who had 4 primary characteristics or 3 primary and 2 secondary criteria were identified as BBS(Table1). Our case had four primary criteriaRetinitis pigmentosa,Obesity, Polydactyly andLearning difficulties thus fulfilling the diagnostic criteria of Bardet-Biedl syndrome. BBS is an

autosomal recessive disorder characterized by nonallelic heterogeneity. BBS is genetically, heterogeneous with four loci mappe to date. These are BBS1 (11q13) ${ }^{\mathbf{1 2}}$, BBS2 (16q22) ${ }^{\mathbf{1 3}}$, BBS3 (3p13) $)^{\mathbf{1 4}}$ , and BBS4 $(15 q 21)^{\mathbf{1 5}}$. We have recently shown that the BBS1 locus is involved in < $45 \%$ of affected white families. The BBS4 locus appears to be the next most common $\mathbf{1 6}$ but there are several families of Middle Eastern and Asian origin which do not show linkage to any known locus. Genotype-phenotype correlations between the various loci do not show obvious differences, With the possible exception of minor effects on growth $\mathbf{6}^{\mathbf{6}}$. The most plausible hypothesis regarding a shared function for BBS proteins

is that they assist microtubule-related transport and cellular organization processes, in particular relating to ciliary/flagellar and centrosomal activities. This hypothesis is supported by several studies using different model organisms $\mathbf{1 7 , 1 8 , 1 9}$. Some of the phenotypes exhibited by BBS proteins, including retinal degeneration, skeletal anomalies and renal cysts or malformations bear resemblance to human diseases associated with abnormal cilia function ${ }^{20}$.

Though a lot of progress has been made about this rare disease, there are still lots more things need to be known about its pathophysiology. Further large scale studies are required to understand the genetic complexity of Bardet-Biedl Syndrome. The disease is incurable, and therefore, persists as a chronic condition. However, timely symptomatic treatment ensures a good prognosis.

\section{Conclusion:}

Further larger scale studies should be conducted in order to understand the exact. Pathogenesis of this syndrome. We presented here a rare syndrome which is more common in male with short stature but can be occurred in a female without short stature as like in our case. In the light of this case, the literature about BBS was reviewed.

\section{Consent:}

Written informed consent was obtained from the patient family for publication of this case report and accompanying images.

\section{References:}

1 Beales PL, Elcioglu N, Woolf AS, Parker D, Flinter FA. New criteria for improved diagnosis of BardetBiedl syndrome: results of a population survey. $\mathrm{J}$ Med Genet. 1999;36:437-46. [PMC free article: PMC1734378] [PubMed: 10874630]

2. Bardet G. Sur un syndrome d'obësitë infantile avec polydactyly et rëtinite pigmentaire. Thesis, University of Paris, France, 1920.

3. Beales PL, Elcioglu N, Woolf AS, Parker D, Flinter FA. New criteria for improved diagnosis of BardetBiedl syndrome: results of a population survey. JMed Genet 1999; 36:437-446.

4. Laurence JZ, Moon RC. Four cases of retinintis pigmentosa occurring in the same family, and accompanied by general imperfections of development. Obes Res 1995; 3:32-41.

5. Schathat AP, Maumenee IH. Bardet-Biedl syndrome and related disorders. Arch Ophthal. 1982. 100: 285-288.

6. Green JS, Parfrey PS, Harnett JD, Farid NR, Cramer BC, Johnson G, et al. The cardinal manifestations of Bardet-Biedl syndrome, a form of Laurence-MoonBiedl syndrome. N Engl J Med 1989; 321:10021009. 
7. Farag, T.I. and Teebi, A.S Highbincidence of Bardet Biedl syndrome among the Bedouin. Clin Genet 1989; 36:463-464.

8. Croft JB, Morrell D, Chase CL and Swift M. Obesity in heterozygous carriers of the gene for the BardetBiedl syndrome. Am J Med Genet 55:12-15,1995.

9. Kenneth lyons Jones. Bardet-Biedl syndrome: Smith's Recognizable Patterns of Human Malformation 5th edition, saunders company; 1997; 590-591.

10. Mehrotra N, Taub S, Covert RF. Hydrometrocolpos as a neonatal manifestation of the Bardet-Biedl syndrome. Am J Med Genet 1997; 69: 220.

11. Stoler JM, Herrin JT, Holmes LB. Genital abnormalities in females with Bardet-Biedl syndrome. Am J Med Genet 1995; 55: 276-278.

12. Leppert M, Baird L, Anderson KL, et al. Bardet-Biedl syndrome is linked to DNA markers on chromosome $11 \mathrm{q}$ and is genetically heterogeneous. Nat Genet 1994; 7:108-12.

13. Kwitek-Black AE, Carmi R, Duyk GM, et al. Linkage of Bardet-Biedl syndrome to chromosome 16q and evidence for non-allelic genetic heterogeneity. Nat Genet 1993; 5:392-6.

14. Sheffield VC, Carmi R, Kwitek-Black A, et al. Identification of a Bardet-Biedl syndrome locus on chromosome 3 and evaluation of an efficient approach to homozygosity mapping. Hum Mol Genet 1994; 3:1331-50.

15. Carmi R, Rokhlina T, Kwitek-Black AE, et al. Use of a DNA pooling strategy to identify a human obesity syndrome locus on chromosome 15 . Hum Mol Genet 1995; 4:9-13.

16. Bruford EA, Riise R, Teague PW, et al. Linkage mapping in 29 Bardet-Biedl syndrome families confirms loci in chromosomal regions $11 \mathrm{q} 13$, 15q22.3-q23, and 16q21 Genomics 1997; 41:93-9.

17. Ansley SJ, Badano JL, Blacque OE, Hill J, Hoskins $\mathrm{BE}$, Leitch $\mathrm{CC}$, et al. Basal body dysfunction is a likely cause of pleiotropic Bardet-Biedl syndrome. Nature 2003; 425:628-633.

18. Li JB, Gerdes JM, Haycraft CJ, Fan Y, Teslovich TM, May-Simera $\mathrm{H}$, et al. Comparative genomics identifies a flagellar and basal body proteome that includes the BBS5 human disease gene. Cell 2004; 117:541-552.

19. Blacque OE, Reardon MJ, Li C, McCarthy J, Mahjoub MR, Ansley S, et al. Loss of C. elegans BBS-7 and BBS- 8 protein function results in cilia defects and compromised intraflagellar transport. Genes Dev 2004; 18:1630-1642.

20. Pazour GJ, Rosenbaum JL. Intraflagellar transport and cilia-dependent diseases. Trends Cell Biol 2000; 12: $551-555$. 